\title{
"Cuerpo de mujer, peligro de muerte": residuos humanos en 2666 de Roberto Bolaño y Chicas muertas de Selva Almada
}

\author{
“Woman's Body: Danger of Death": Human Waste in Roberto Bolaño's 2666 and \\ Selva Almada's Chicas muertas
}

Virginia HOLZER*

Universität Zürich (UZH)

\author{
Carmen CARRASCO LUJÁN** \\ Université de Genève (UNIGE)
}

\begin{abstract}
RESUMEN: En este artículo proponemos una lectura de los feminicidios representados en la cuarta parte de 2666 (2004) de Roberto Bolaño ("La parte de los crímenes") y en Chicas muertas (2014) de Selva Almada a partir de lo que entendemos como "basurización" del cuerpo femenino. Esta basurización es provocada, según las narraciones, por diversos factores, entre los que proponemos juegan un papel central la neoliberalización de la economía, un discurso machista (violencia simbólica), la impunidad y la desensibilización de los ciudadanos mediante la repetición de estos crímenes, es decir, su exceso.
\end{abstract}

PALABRAS CLAVE: Feminicidios. Neoliberalismo. Residuos humanos. Exceso. Impunidad.

ABSTRACT: In this article we propose a reading of the feminicides represented in the fourth part of 2666 (2004) by Roberto Bolaño ("The Part about the Crimes") and in Chicas muertas [Dead Girls] (2014) by Selva Almada based on what we understand as "basurización" [symbolic trashing] of the female body. This trashing is provoked, according to the texts, by various factors, among which we propose the central role of the neoliberalization of the economy, a macho discourse (symbolic violence), impunity and the desensitization of the citizens through the repetition of these crimes, that is, their excess.

KEYWORDS: Feminicides. Patriarchy. Neoliberalism. Human waste. Excess. Impunity

Tiradas a la basura en la bolsa de consorcio: igual que se tira unforro, la cáscara del zapallo, los papeles que no sirven y los huesos del asado entre tantas otras cosas. Tiradas como si nada, como objetos de consumo que ya fueron consumidos.

"Basura”, Gabriela Cabezón Cámara.

\footnotetext{
* Magísterpor la Universidad de Berna en Lengua y literaturas hispánicas y en Estudios latinoamericanos. Actualmente cursa un doctorado en Literatura hispanoamericana, en la Universidad de Zúrich, Seminario románico, Suiza.E-mail: virginia.holzer@rom.uzh.ch

*** Magíster por la universidad de Ginebra en Estudios hispánicos y en Literatura comparada. Actualmente cursa un doctorado en Estudios hispánicos, en la Universidad de Ginebra, Departamento de lenguas y literaturas romances, Suiza.E-mail: ccarrasco.lujan@gmail.com
} 


\section{Introducción}

A primera vista, la cuarta parte ("La parte de los crímenes") de 2666 (2004) de Roberto Bolaño y Chicas muertas (2014) de Selva Almada tienen un punto en común: se trata de narraciones híbridas sobre feminicidios cuya resolución judicial se manifiesta problemática, lo cual permite abordar desde distintas perspectivas las razones de la impunidad. Una lectura atenta nos permite encontrarAotras similitudes,oeomo la relación metafórica entre los lugares (vertederos, acequias, etc.) en que son encontrados los cadáveres y los cuerpos femeninos considerados como desechos. En este artículo, precisamente, queremos problematizar la "basurización" del cuerpo de la mujer que intentan representar nuestros dos escritores. A través del análisis de estos dos textos que representan a víctimas de feminicidio, víctimas de vidas "precarias" — tal y como esta condición es definida por Judith Butler (2010)_, queremos investigar las causas que son representad as como originarias de esos crímenes, así como los factores que inciden en su repetición y en su impunidad.

En la cuarta parte de su novela póstuma 2666, el escritor chileno Roberto Bolaño representa los feminicidios que tienen lugar durante más de una década en Santa Teresa, ciudad ficcional basada en Ciudad Juárez, en el norte mexicano. Como en la vida real, Santa Teresa es un lugar de paso de migrantes en su viaje hasta los Estados Unidos, así como un lugar de llegada para migrantes del sur que llegan para trabajar en la industria maquiladora. Allí, como en la ciudad en la cual la novela se basa, las víctimas de los crímenes sexuales, torturas y asesinatos son en su mayoría mujeres migrantes trabajadoras de las maquiladoras, de negocios locales y trabajadoras sexuales. En las líneas que siguen intentaremos demostrar que en 2666 se propone que el asesinato de mujeres tiene como condiciones de posibilidad la violencia simbólica y el sistema económico-social del neoliberalismo. Estos factores convergen en la cosificación del cuerpo femenino, el cual, una vez consumido o llevado al límite de la precariedad, se convierte en un mero desecho de la sociedad. En cuanto a Chicas Muertas (2014) de Selva Almada, se presenta como un texto híbrido que atraviesa fundamentalmente el género testimonial y la novela de no ficción. La obra indaga en la reconstrucción de tres crímenes de mujeres que quedaron impunes. Mediante la integración de diversas fuentes, como el testimonio de los familiares de las víctimas, el acceso a las causas judiciales y periódicos de la época, 
restituye de algún modo la voz de estas jóvenes. Entonces, en la parte donde analizamos esta novela, profundizamos en otros aspectos de la "basurización" del cuerpo de las mujeres: el exceso (BAUMAN, 2017) y su efecto desensibilizador (SEGATO, 2016). Sugeriremos como factores adicionales en la producción de un contexto de violencia, la impunidad y la exclusión (CASTILLO DURANTE, 1999).

Como mencionamos líneas arriba, consideramos en nuestra lectura que los cuerpos femeninos son "basurizados", y para estudiar las implicancias de este proceso nos basamos en lo propuesto por Daniel Castillo Durante (1999) como lógica de basurización. Si bien esta propuesta fue formulada por Castillo Durante para pensar a Latinoamérica como vertedero de la posmodernidad en su relación económica y social con los países del Norte global, el valor de la misma radica en la apertura de su enfoque hacia el ámbito simbólico. Su concepción es definida como la puesta en escena de mecanismos de exclusión de aquello que puede vulnerabilizar el sistema. En otras palabras, el rechazo de la otredad a través de su evacuación, su desecho.

\section{Politización de la violencia en 2666}

Aunque no es nuestra intención extendernos aquí sobre las hipótesis que han sido planteadas en cuanto a las posibles causas de los feminicidios en Ciudad Juárez y a los factores responsables de la impunidad, podemos mencionar que entre los últimos años de la década del noventa y primeros del 2000 se publicaron numerosas investigaciones académicas y periodísticas que contribuyeron a esclarecer (o a veces, a mistificar) este complejo fenómeno. Desde la semiótica (SEGATO, 2013), la sociología y la antropología (WASHINGTON VALDEZ, 2005), y el periodismo (GONZÁLEZ RODRÍGUEZ, 2002), estas investigaciones abordaban diversas aristas del problema, como el impacto del acuerdo NAFTA en la zona fronteriza y la precarización de los trabajadores de las maquilad oras, así como los posibles nexos entre el crimen organizado, el tráfico de drogas y autoridades corruptas. Uno de los trabajos periodísticos de importancia es el de Sergio González Rodríguez, reunido en el libro Huesos en el desierto (2002), el cual nos ayuda además a entender 2666, pues Bolaño lo utiliza como subtexto de su propia novela y el propio González aparece como personaje en ella. Sin embargo, las hipótesis sobre las causas de los feminicidios difieren notablemente entre el ensayo periodístico mencionado y nuestra novela. Sergio González considera tres hipótesis: la de dos asesinos seriales; la 
de los asesinatos rituales en "orgías sexuales y de fraternidad" (2002, p. 251) de personajes poderosos de la ciudad; y la de crímenes orquestados por empresarios y políticos con el fin de crear un clima de inseguridad a través del cual reafirmar su dominio. Se ha discutido antes cómo estas interpretaciones tienen como limitación principal que producen un "vaciamiento de lo político" (ZAVALA, 2016, p. 122) que impide considerar la profunda responsabilidad del Estado. Como veremos, en 2666, por el contrario, se descarta la hipótesis del asesino serial y se repolitizan los crímenes tanto en su dimensión estatal como social. Para ese efecto, los asesinatos son puestos en un contexto de profunda complicidad entre el Estado y el crimen organizado, de neoliberalización de la economía, así como de violencia simbólica hacia las mujeres, la cual permea todas las relaciones sociales.

\section{Violencia simbólica y cuerpo femenino}

En 2666, la violencia simbólica ${ }^{1}$ hacia las mujeres parece abarcar todo el espectro de relaciones sociales que son representadas. Presente en las fuerzas del orden, las autoridades políticas y la sociedad civil, la ubicuidad de esta violencia parecería demostrar la tesis feminista de que los crímenes sexuales son "expresiones de una estructura simbólica profunda que organiza nuestros actos y nuestras fantasías y les confiere inteligibilidad" (SEGATO, 2013, p. 19). Al inicio de "La parte de los crímenes", cuando aparecen los primeros cadáveres, las autoridades no dedican los esfuerzos que deberían para resolver los crímenes, hasta que estos ganan visibilidad en los medios de comunicación. Entonces la policía dedica más recursos, aunque principalmente con el fin de limpiar su propia imagen y la imagen de la ciudad que el de resolver los delitos. Esto se explica en parte debido a la misoginia presente en el cuerpo de policías. Podemos leer una serie de chistes que se cuentan los policías entre las páginas 689-692. Chistes como: “a ver, valedores, defínanme una mujer. Silencio. Y la respuesta: pues un conjunto de células medianamente organizadas que rodean a una vagina” (BOLAÑO, 2004, p. 690);

\footnotetext{
${ }^{1}$ De hecho, la violencia representada en la novela es múltiple, pero ateniéndonos a la cla sificación de Slavoj Žižek (2008), reconocemos tres formas de violencia: sistémica, simbólica y subjetiva. Esta última es la más visible, pues es realizada por un agente o sujeto identificable. La violencia simbólica, por su parte, "embodied in language and its forms" (ŽIŽEK, 2008, p. 1), tiene que ver con la reproducción de las relaciones de poder no solo a través del discurso sino a través "its imposition of a certain universe of meaning” (2008, p. 1). Finalmente, la violencia sistémica, la más invisible, por la cual los sujetos que la padecen son relegados a situaciones extremamente precarias sin saber quién es el culpable.
} 
y que tienen como conclusión por parte de un judicial: "las mujeres son como las leyes, fueron hechas para ser violadas" (2004, p. 691). Asimismo, en varias ocasiones los policías sospechan que la víctima es una prostituta debido a su vestimenta, aunque esta última pueda ser tan sólo "un par de zapatos de tacón alto, de cuero" (2004, p. 790-791). La atribución de este trabajo precario a cualquier mujer que ha sido asesinada impide de manera inmediata, para esta policía, asumir la responsabilidad de resolver tras crimen, pues consideran las vidas precarias como no merecedoras de duelo-por consiguiente, ni de investigación- como veremos más adelante.

No sólo es representado el desinterés por parte de la policía, sino que esta llega a perpetrar abusos contra mujeres. Se narra por ejemplo cómo un grupo policías inculpa erróneamente de uno de los asesinatos a un grupo de prostitutas, y para "castigarlas" organizan una orgía en la misma delegación policial donde las violan (2004, p. 502). Si bien se relatan otro tipo de excesos policiales con los sospechosos de los crímenes, como tortura psicológica y física en el caso de hombres, la violación sexual a mujeres por parte de la policía indica un desprecio por los derechos sexuales por la misma autoridad encargada de resolver otros crímenes sexuales. La misoginia de las fuerzas del orden es solo el reflejo de la violencia simbólica que permea todos los estratos de la sociedad. De los crímenes resueltos (que constituyen el 10\% del total de víctimas documentadas), la mayor parte fueron cometidos por las parejas, exparejas o pretendientes de las víctimas. Todos ellos toman posesión de los cuerpos femeninos para dejar en claro la dominación masculina. Si consideramos que los crímenes contra mujeres están "íntimamente relacionados en proporción directa con el grado de tolerancia que cada sociedad manifieste en torno a los mismos y a su nivel de violencia" (MONÁRREZ FRAGOSO, 2000, p. 92), en 2666 se demuestra cómo la misoginia determina la prevalencia de los feminicidios.

\section{Desechos de la industria maquiladora}

El estilo en la "Parte de los crímenes" es impersonal, parecido a un informe de medicina forense en su descripción de los cadáveres. Este tiene la finalidad de recrear la situación en que viven las mujeres: como señala Manuel Asensi, en esta parte de la novela la subjetivación desaparece pues "dado que las verdaderas protagonistas son mujeres 
asesinadas, la subjetividad, la femenina y subalterna, ha sido borrada del mapa, reducida al silencio y destruida" (ASENSI, 2010, p. 358). A pesar del borramiento de estas subjetividades, el narrador reconstruye lo que estas podrían haber sido a través de la revelación de detalles sobre la identidad de las mujeres. Esto ocurre a contramano de lo que proponen los análisis en torno a los feminicidios en Ciudad Juárez, pues como señala Monárrez Fragoso, estos destacan los lugares donde fueron encontrados los cuerpos zonas desérticas, basureros, riveras y alcantarillas-, opacando otras informaciones relevantes como la extracción social de las víctimas, su identidad, de manera tal que son de cierta forma cosificadas (2010, p. 59). En 2666, a pesar del estilo impersonal, el narrador describe las actividades a las que se dedicaban las víctimas: la mayoría de ellas eran operarias de las maquiladoras de Santa Teresa. Entre los cuerpos que no son reconocidos, se supone en la novela que algunas de las mujeres son migrantes que llegan desde el Sur para pasar a Estados Unidos o trabajar en Santa Teresa; o bien son trabajadoras sexuales. Lo que queda claro es que en 2666 las víctimas de los crímenes llevaban vidas precarias. Como señala uno de los personajes, la profesora Pérez, a Amalfitano -quien temía que su hija fuera víctima de los crímenes- "las víctimas solían ser secuestradas en otras zonas de la ciudad" (BOLAÑO, 2004, p. 255) pues no son crímenes que ocurran a la clase media, sino sólo a la clase baja.

La precariedad también abarca las condiciones de trabajo en un contexto neoliberal. En las maquiladoras, las operarias se encuentran en condiciones de trabajo de explotación:

Sólo una de las maquiladoras tenía cantina para los trabajadores. En las otras los obreros comían junto a sus máquinas o formando corrillos en cualquier rincón. Allí hablaban y se reían hasta que sonaba la sirena que marcaba elfin de la comida. La mayoría eran mujeres. (2004: 449)

Asimismo, se relatan casos de mujeres que son despedidas de sus puestos de trabajo por intentar organizar sindicatos (2004, p. 634 y 721). El desprecio de parte de la jerarquía de la industria maquiladora por la suerte de las trabajadoras se ve reflejado en el caso de dos niñas secuestradas, cuya vecina quiere alertar a su madre que trabaja en una de las fábricas, pero no lo consigue pues "estaban prohibidas las llamadas privadas y le colgaron". Intenta entonces llamar al padre de las niñas que trabaja en la misma maquiladora pues la madre al ser operaria "era sin duda considerada de un rango inferior, es decir prescindible en cualquier momento o por cualquier razón o capricho de la razón" 
(2004, p. 659). Las mujeres son consideradas en el marco del trabajo en la industria maquiladora como piezas "prescindibles", al tiempo de que esta industria depende de ellas para subsistir, es decir, son en realidad imprescindibles para permitir su buen funcionamiento.

En Marcos de guerra, Judith Butler señala que "la precariedad subraya nuestra radical sustituibilidad y nuestro anonimato con relación tanto a ciertos modos socialmente facilitados de morir y de muerte como a otros modos socialmente condicionados de persistir y prosperar" (2010: 31). Las vidas de las operarias de las maquiladoras son sustituibles pues son consideradas meras piezas de un engranaje. Como piezas anónimas, estas mujeres de vidas precarias son asesinadas y sus cuerpos son depositados en basureros de las maquiladoras: "En el basurero donde se encontró a la muerta no sólo se acumulaban los restos de los habitantes de las casuchas sino también los desperdicios de cada maquiladora" (BOLAÑO, 2004, p. 449). Otras son encontradas en otros basureros. Así, la vida de las mujeres se encuentra en un ciclo de producción que conlleva al consumo de su cuerpo (capacidad de trabajo/reproducción) y luego a su basurización. Analizando la muerte de vidas precarias en casos de guerra, Butler señala que la “capacidad de ser llorado" es un presupuesto de las vidas que importan (2010, p. 32). La creación de nuestra percepción de vidas precarias tiene que ver con la creación de afectos que nos permiten asimilar esas vidas como desechables. Para ese efecto, según Butler, juegan un papel notable los medios de comunicación. En 2666, para representar el poco interés que generan en un inicio los feminicidios, el narrador pone en escena a un delincuente que orina en las Iglesias, y que consigue "mayor eco en la prensa local que las mujeres asesinadas en los meses precedentes" (2004, p. 459). Estos ataques consiguen que incluso la prensa nacional se interese por el caso, enviando periodistas a Santa Teresa para investigar al llamado "Penitente"2. Así, se nos muestra que las muertes de las mujeres no son dignas de duelo por parte de la opinión pública, pues no se les dedica el espacio ni el interés que requieren. En 2666, Bolaño es consciente de la creación de "vidas que importan" y otras que no. Al respecto, es significativo un pasaje que pertenece a "La parte de Fate", donde un personaje reflexiona sobre la importancia de la vida y la muerte de personas en la opinión pública según su origen:

\footnotetext{
2 Y no solo consigue mayor atención en los médios de comunicación, sino que la policía se pa sa veinticuatro horas del día vigilando las iglesias de la ciudad (2004: 507).
} 
En el siglo XVII, por ejemplo, en cada viaje de un barco negrero moría por lo menos un veinte por ciento de la mercadería, es decir, de la gente de color que era transportada para ser vendida, digamos, en Virginia. Y eso ni conmovía a nadie ni salía en grandes titulares en el periódico de Virginia [...]. Si, por el contrario, un hacenda do sufría una crisis de locura y ma taba a su vecino y luego volvía galopando hacia su casa en donde nada más descabalgar mataba a su mujer, en totaldos muertes, la sociedad virginiana vivía a temoriza da al menos durante seis meses, y la leyenda del asesino a caballo podía perdurar durante generaciones enteras. (2004, p. 338)

Al preguntarse por esta desproporción, concluye que "la gente de color muerta en el barco no pertenecía a la sociedad, mientras que [...] el asesino a caballo de Virginia sí [...], es decir, lo que a [él le] les sucediera era escribible, era legible” (2004, p. 339). A partir de esta cita, podemos entender mejor lo que afirma uno de los personajes: "nadie presta atención a estos asesinatos, pero en ellos se esconde el secreto del mundo" (2004, p. 439). Como si se tratase de un acertijo, justamente el secreto del mundo consiste en que nadie presta atención a esos asesinatos, de que hay vidas que importan y que son lloradas, y otras que no, pues no son "escribibles" (2004, p. 339). De allí que en esta novela Bolaño confirme una ética como escritor de volver "escribible" el destino trágico de cientos de mujeres cuyas vidas (y muertes) han sido basurizadas.

Como mencionamos en un principio, Bolaño no elude la responsabilidad política en los crímenes de Santa Teresa. Para ello, retrata la complicidad entre el gobierno y el crimen organizado, y una política de seguridad más interesada en resguardar la imagen de la ciudad que en resolver los crímenes $^{3}$. Por ejemplo, el propio jefe de la policía de Santa Teresa provee de hombres de seguridad a un narcotraficante de la zona. Y en una emboscada a la esposa de este narcotraficante, uno de los sicarios asesinado es luego reconocido como un agente judicial del estado. De otro lado, la desaparición de Kelly Rivera Parker, y la implicación de su amiga, una diputada del PRI, a través de un detective, lleva a identificar lo que nos parece la hipótesis más fuerte del libro, según la cual, poderosos magnates de Santa Teresa estarían implicados en los crímenes, los cuales se llevan a cabo en orgías rituales. De hecho, se trata de una de las hipótesis manejadas por investigadores del caso, entre ellos, Sergio González Rodríguez en Huesos en el desierto. La novela de Bolaño, sin embargo, se limita a exponer los nexos reales entre narcotraficantes, banqueros, empresarios, y "otras personalidades de la sociedad, del

\footnotetext{
${ }^{3}$ Lo cual también ocurría en Ciudad Juárez, como señalan Domínguez-Ruvalcaba y Ravelo Blancas (2010: 182).
} 
crimen y de la política” (2004, p. 786). Aunque la diputada del PRI que ha ordenado la investigación privada en un inicio se muestra descontenta con las hipótesis que intentan mitologizar la violencia en México: "Estoy harta de los mexicanos que hablan y se comportan como si todo esto fuera Pedro Páramo" (2004, p. 779-780); finalmente termina aceptando que lo que se esconde detrás de los crímenes es muy complejo y probablemente abarca los propios círculos de poder a los que ella pertenece.

Las sugerencias de sospechosos en "La parte de los crímenes" siempre están seguidas de nuevos hallazgos de cadáveres, como si fuese imposible dar con los responsables de los feminicidios, pues la violencia a la que están sometidas las mujeres es estructural y no depende de un grupo identificable de culpables.

\section{Horror y tipificación de la violencia en Chicas muertas}

"No quiero conocer mi futuro. No quiero que saque a la luz ningún quiste del pasado" (ALMADA, 2014, p. 46). Estas palabras son la expresión del pensamiento interno de la escritora argentina Selva Almada al consultarle a una tarotista sobre la desaparición y muerte impune de tres jóvenes en la década del 80. Sin advertirlo, la investigación de esos crímenes plasmada en la novela de no ficción Chicas muertas (2014) resultó en la expulsión de un exceso de memoria(s) en torno a la(s) violencia(s) contra las mujeres. Bajo la metáfora del "quiste", podemos interpretar los recuerdos y la propia de experiencia de la narradora-autora como algo que por su exceso y horror no puede ser asimilado y, por tanto, necesario de extirpar. Hace treinta años el "quiste" aún no era llamado feminicidio, y el sinnúmero de muertes que implicó tampoco fueron reconocidas como tal. Pero de todas hubo una que dejó su marca en Almada. A pocos años de restaurada la democracia en la Argentina y en la tranquilidad de un domingo en familia, la noticia del asesinato de Andrea Danne, una adolescente de un pueblo vecino, le "llegó como una revelación" (2014, p. 17). La "revelación” que la autora tuvo a los trece años no es otra cosa que la conciencia apocalíptica de un mundo en el que la amenaza de muerte para las mujeres irrumpe en la cotidianidad. La muerte violenta de esa joven en 1986 (apuñalada en su propia cama, la noche anterior a su primer examen final de profesorado, mientras sus padres dormían en la habitación de al lado) provoca en Almada un sentimiento de repulsión: "Mi casa, la casa de cualquier adolescente, no era el lugar más seguro del mundo. Adentro de tu casa podían matarte. El horror podía vivir 
bajo el mismo techo" (2014, p. 17). Más que el miedo, el horror tiene que ver con la repugnancia. Esta reacción instintiva ante la violencia es analizada por Adriana Cavarero, quien en su trabajo Horrorism (2009) señala la importancia de nombrar la violencia contemporánea ante la insuficiencia de los nombres y conceptos, el horror, a diferencia del terror, paraliza. Como explica Cavarero, horror deriva etimológicamente del verbo en latín horreo, que, como el griego phrisso, alude a la sensación de encresparse, como cuand o el vello se eriza. La aversión de la joven Almada ante la noticia de la chica muerta, que bien podría haber sido ella, confirma lo que Cavarero define como la física del horror:

\begin{abstract}
[an] instinctive disgust for a violence that, not content merely to kill because killing would be too little, aims to destroy the uniqueness of the body, tearing at its constitutive vulnerability. What is at a stake is not the end of a human life but the human condition itself, as incarnated in the singularity of vulnerable bodies. $(2009, \text { p. } 5)^{4}$
\end{abstract}

Los tres crímenes, que atentaron contra la dignidad de las chicas asesinadas en la década del ochenta, se van reconstruyendo en la novela al igual que los huesos que reúne "la huesera" del mito cheroqui que una tarotista le narra a la escritora. Frente a la ubicuidad de una violencia que borra toda individualidad, el entramado de las voces de familiares y amigos que se yuxtaponen para memorar a las víctimas restituye, en parte, algo de la humanidad que le fue arrebatada a esos cuerpos.

En la Argentina, tuvieron que pasar décadas para que el feminicidio se nombre como tal y se instale como problema social. Como argumenta Rita Segato al hablar sobre la importancia de tipificar los diversos tipos de violencia contra mujer,

[...] es indispensable tanto para la eficacia de la investigación criminal, como para la comprensión de los crímenes por parte de los jueces y, especialmente, para crear las condiciones de que por lo menos una parte de esos crímenes se tornen jurisdicción de los fueros internacionales de Derechos Humanos y alcancen la condición de imprescriptibles, es decir, QUE NO PRESCRIBAN. (2012)

\footnotetext{
4 “[un] asco instintivo por una violencia que, no contentándose con meramente matar porque matar sería muy poco, pretende destruir la singularidad del cuerpo, desga rrando su vulnerabilidad constitutiva. Lo que está en juego no es el fin de una vida humana sino la propia condición humana, encarnada en la singularidad de cuerpos vulnerables" (la traducción es nuestra).
} 
Hasta la actualidad, ninguno de los tres crímenes fue resuelto, con lo cual la narración en la voz de la escritora repone en el presente una justicia simbólica que expone la sistematicidad de la violencia contra las mujeres aún vigente. La invisibilización que implica el fenómeno de basurización del cuerpo de las mujeres puede ser relacionada con la reflexión que Zygmunt Bauman plantea en Vidas desperdiciadas (2005). Su escrito problematiza la producción de "residuos humanos" en la sociedad moderna, cuya estrategia subyacente y efecto ineludible reside en la división entre "lo que cuenta" y "lo que no cuenta", "producto útil y residuos". El filósofo parte del ejemplo de la ciudad de Leonia, lugar ficticio de Las ciudades invisibles (2021 [1972]) de Italo Calvino, donde la obnubilación por el consumo de nuevos productos tiene una creciente producción de desechos, aspecto que los habitantes prefieren ignorar porque tienen la seguridad de que "todo va a parar al vertedero". Sólo piensan en este cuando "la avalancha de sobras desciende de las montañas de basura y atraviesa las vallas destinadas a proteger nuestro propio patio trasero" (BAUMAN, 2017, p. 42). El ejemplo le sirve a Bauman para establecer su comparación con la indiferencia en los países del Norte global ante la producción masiva de refugiados, entre otros parias de la modernidad. En relación dialógica con la preocupación de los leonianos por aquello que quisieran no ver, el mensaje de la desgracia en el relato de Almada conmocionó a todos cuando llegó a su propio pueblo.

\section{La espiral autopropulsora del cuerpo de las mujeres}

En un contexto movilizado por el retorno a la democracia y el juicio a las juntas militares responsables de la violencia y atrocidades del pasado reciente, la montaña de mujeres víctimas de la violencia de género crece como secreto oscuro y vergonzoso en cada rumor, historia, y experiencia de violencia compartida entre las mujeres del pueblo. La transmisión oral de este tipo de relatos que fueron sedimentánd ose en la memoria de Almada, también dejó su huella. Desde la vecina golpeada por su pareja; la mamá de una amiga que no podía maquillarse porque su marido no se lo permitía; la colega de su madre que trabajaba para entregarle a su marido su sueldo completo; hasta la experiencia de su madre y tía también afectadas por la agresión verbal y física de un hombre (2014, p. 56). En línea con la lectura que Castillo Durante hace de Latinoamérica bajo la lógica del 
vertedero, vemos en la multiplicación de casos de violencia contra las mujeres lo que el autor entiende por "basurización" del otro. En nuestro análisis, la otredad construida dentro de un orden patriarcal tiene como referente inmediato a la mujer. Es sobre el cuerpo de las mujeres que se despliega esa "puesta en escena de mecanismos de descongestión” (CASTILLO DURANTE, 1999, p. 235). Bajo esta lectura, el reciclaje de la basura, aquí reproducido a través de las historias y casos de mujeres violentadas, asesinadas, que se suceden una tras otra, constituye la clave que permite a la maquinaria de sometimiento seguir su producción.

Lo anterior nos lleva a plantear otro aspecto de la basurización: el exceso, "ese fiel e incondicional aliado y cómplice del residuo" (BAUMAN, 2005, p. 40). Tal como Almada lo señala en su epílogo, el aumento de forma exponencial de femicidios en la Argentina llevaría a entender la división entre "lo que queda" y "lo que sigue" en el camino de las mujeres al vertedero como "una cuestión de suerte" (182). El exceso de cadáveres, más que atestiguar la omnipresencia de la violencia, expone el valor del desecho como la condición misma de posibilidad del consumo del cuerpo de las mujeres. Operación que se traduce en la espiral autopropulsora de chicas muertas. Es decir que, en la medida en que todo cuerpo de mujer es apropiable, y por tanto dominado, torturado, violado, quemado, asesinado, arrojado, desechado, expulsado; sólo un consumo de manera exponencial puede dar la ilusión de continuidad necesaria al ciclo de producción gestionada por los perpetrad ores. La muerte de María Luisa Quevedo en 1983, "una chica menudita" (24) de "piel morena" (109), en la ciudad Sáenz Peña de la provincia de Chaco, constata la actividad autopropulsora en la producción de residuos humanos. La adolescente de quince años había salido a las tres de la tarde de la casa donde trabajaba de mucama — otra vida precaria, mestiza y pobre — cuando fue vista por última vez. Tres días después fue encontrada en de la periferia de la ciudad:

\footnotetext{
De estos terrenos, ahora abandonados, en una época se había extraído tiema para fabricar ladrillos y había quedado una exca vación de poca profundidad y grandes dimensiones que, cuando llovía, se llenaba de agua, formando una laguna que en la zona llaman represa. En esta represita con poca agua, abandonaron elcuerpo de la chica. (ALMADA, 2014, p. 26)
}

La relación de contigüidad entre el cuerpo desechado de la joven que había sido violada y estrangulada, y el baldío abandonad o donde fue encontrado, pone de relieve las formas de explotación de lo que puede ser transformado en "mercancía" (cuerpo de mujer 
y ladrillo) en la sociedad moderna. Una vez expropiado de su valor, el cuerpo de María Luisa fue descartado en el espacio público para que sea encontrado en la mañana de un domingo. Nuevamente, la repetición de la escena violenta. Pero la irrupción del horror en la "tranquilidad" de un pueblo, como en el caso de Andrea, no es casual. Como Segato afirma, al exponer su tesis en torno a la "pedagogía de la crueldad" (2016), es en el cuerpo de la mujer que la crueldad se inscribe como mensaje frente a una colectividad. La exhibición de ese cuerpo tiene por objeto mostrar a los residentes del lugar la agresividad y poder de muerte de la "fratría mafiosa", porque como sostiene la antropóloga, la violación letal no puede sino ser entendida como crimen organizado. Pero la mostración también conlleva el mensaje de que su control sobre el territorio (cuerpo femenino en metonimia con la ciudad) es total. La escenificación del acto violento y su omnipresencia por vía de la repetición no sólo siembra terror, también produce una desensibilización en la ciudadanía. A diferencia del caso Andrea Danne, que tuvo cobertura en los medios de comunicación incluso nacionales, el de Quevedo fue tratado "con pluma novelesca por la prensa local" (2014, p. 151), opacado por el clima festivo ante el retorno de la democracia. Este es otro crimen impune, en el que el "totalitarismo de provincia" (SEGATO, 2016) está representado por un sexagenario, dueño de una empresa de transporte. La familia Quevedo cree que él es el asesino, y que por su fortuna y poder desplegó una red de alianzas para desviar la causa: desidia policial, falsos testimonios, hasta la muerte de un aborigen que vagabundeaba en la "represita".

A partir de la investigación realizada por Almada, y en consonancia con la hipótesis de Segato sobre los crímenes de Juárez, los feminicidios "se pueden comprender mejor si dejamos de pensarlos como consecuencia de la impunidad e imaginamos que se comportan como productores y reproductores de impunidad" (2016, p. 43). Los pactos de silencio de la "hermandad viril", aquí formada por la policía, la justicia, los empresarios, los políticos, sostienen ese orden patriarcal cuya marca es la "dueñidad", incluso de los cuerpos. El tercer caso que Almada estudia da prueba de esto, donde la impunidad, más que la causa es el resultado de estos crímenes. Sarita Mundín, una joven de veinte años de la provincia de Córdoba, desaparece en 1988 luego de salir con su amante, un hombre casado, dueño de un frigorífico en la zona. En un contexto de pobreza, siendo madre y a cargo de su madre y hermana, ejerce la prostitución, otra vida precaria. De entre sus clientes, algunos eran miembros de un partido político, pero con Olivero, principal sospechoso, estableció una relación que estaba llegando a su fin. Después de nueve meses

Revista Moara, n. 59, ago-dez 2021 ISSN: 0104-0944 
aparecieron los restos de una mujer. La hermana de Sarita tuvo que reconocer el cadáver, pero el estado de los huesos, "pelados", y las piezas dentarias distaban de la Sarita que había visto partir:

\begin{abstract}
El esqueleto se encontró en una punta de la isla, en el paraje La Herradura, en una enramada producida por la creciente del lecho del río Tcalamochita, conformada por un árbol caído e incrustaciones de palos y troncos, como así de desechos arrastrados por el agua (frascos, tergopol). Los restos se encontraban en posición transversal con respecto al lecho del río [...]. El esqueleto se encontraba más desmenuzado en su parte posterior que anterior. Presentaba prendas femeninas: bombacha, corpiño, pollera y restos de una chomba.(ALMADA, 2014,p. 126)
\end{abstract}

La descripción del hallazgo, que figura en el expediente, da cuenta de cómo el deterioro del cuerpo está en equivalencia con el lugar deteriorado del río, donde conviven desechos industriales y desechos humanos. En la entrevista con la escritora, la joven confiesa que un funcionario le hizo firmar el acta de reconocimiento del cuerpo. Este caso también quedó impune. Diez años más tarde, cuando los familiares pidieron un estudio de ADN el resultad o fue negativo. El "cuerpo sin tregua" (GAYOL y KESSLER, 2018) de Sarita, sin paz, exhumado, analizado, termina revelando "que hay otra mujer muerta por la que nadie reclama o a la que todavía su familia la sigue buscando: ese atadito de huesos que enterraron con el nombre de Sarita" (ALMADA, 2014, p. 128). La yuxtaposición de cuerpos que importan y cuerpos que (no) importan, y que la investigación de Almada revela, nos obliga a reflexionar sobre el valor diferenciado de la vida (BUTLER, 2010). Esos residuos humanos, que como el fiscal la sociedad preferiría archivar, silenciar, no ver, retornan como restos que no permiten que se los pase por alto. De manera significativa, es justamente el exceso, en tanto condición necesaria para la continuidad de producción de residuos, lo que viene a arrojar luz sobre los pactos secretos de esa comunidad nefasta de hombres. Y es por su carácter de excluido, que el cuerpo de las mujeres víctimas de la violencia de género se incluye en la noción de "residuos humanos" (BAUMAN, 2005): vidas sin valor; vidas que no están en condiciones de escoger; marcadas por su condición de "deriva liminar", en una zona gris, dentro y fuera del universo humano. Como la vida de Sarita, de quien se cree que fue vendida a una red de trata en España. En resumen, mientras las mujeres desaparecen (en vida y con la muerte), los “dueños" se siguen atribuyendo la capacidad de dañar impunemente. 


\section{Conclusiones}

A través del análisis de la representación del femicidio en las dos novelas contemporáneas, 2666 y Chicas muertas, sugerimos dos aspectos que pueden entenderse como regularidades en este tipo de escrituras. Por una parte, los procesos de basurización, tanto material como simbólica, del cuerpo de las mujeres que conllevan implícitamente la cosificación de este para ser transformado en materia de consumo y luego ser descartado. Dicho proceso solo puede ser interpretado y cuestionad o en el contexto actual de las economías neoliberales que fomentan estas lógicas, escenario en el que como hemos demostrado son las vidas precarias las que están más expuestas a ser excluidas. Por otra parte, el exceso como condición fundamental en la producción de cuerpos residuales, como dijimos anteriormente, genera la ilusión de que la cadena expulsora de residuos humanos nunca para. Sin embargo, es por su misma emergencia que se logra atisbar el funcionamiento de esa lógica residual, sus agentes basurizadores, los pactos de silencio que los mancomunan.

Sin la intención de dar respuestas a un tema que todavía necesita ser ampliamente discutido, planteamos más bien algunas interrogantes entorno al mismo. En ambos relatos, el derrotero por resolver los crímenes termina en eso, un camino que no llega a destino. ¿Qué otras respuestas puede ofrecer la literatura en un contexto en el que la impunidad más que la causa es el resultado de estos crímenes? El desafío es grande, pero la posibilidad que ofrecen estas escrituras al alumbrar los mecanismos de anulación cruel y letal es esperanzador: interpelarnos en la reflexión y preocupación por un problema que hace décadas que reclama ser atendido.

\section{Bibliografía citada}

ALMADA, S. Chicas muertas. Buenos Aires: Random House, 2014.

ASENSI PÉREZ, M. Atreverse a mirar por el agujero. Lo político y lo real en 2666 de Roberto Bolaño. In: RÍOS, F. (ed.). Roberto Bolaño: ruptura y violencia en la literatura finisecular. Puebla: Eón, 2010. p. 343-368.

BAUMAN, Z. Vidas desperdiciadas. La modernidad y sus parias. Barcelona/Buenos Aires/México: Paidós, 2017.

BOLAÑO, R. 2666. Barcelona: Anagrama, 2004. 
BUTLER, J. Marcos de guerra. Las vidas lloradas. México D.F.: Paidós, 2010.

CABEZÓN CÁMARA, G. Basura. Revista Anfibia. Disponible en: http://revistaanfibia.com/ensayo/basura/ Acceso el: 15/09/2021.

CALVINO, I. Las ciudades invisibles. Madrid: Siruela, 2021 [1972].

CASTILLO DURANTE, D. Culturas excrementicias y postcolonialismo. In: DE TORO, A. y DE TORO, F. (eds.). El debate de la postcolonialidad en Latinoamérica. Frankfurt am Main/Madrid: Vervuert/Iberoamericana, 1999. p. 235-257.

CAVARERO, A. Horrorism. New York: Columbia Unversity Press, 2009.

DOMÍNGUEZ-RUVALCABA, H. Y RAVELO BLANCAS, P. Obedience without Compliance. The role of the government, organized crime, and NGOs in the system of impunity that murders the women of Ciudad Juárez. In: FREGOSO, R. y BEJARANO C. (eds.). Terrorizing Women. Feminicide in the Américas. Durham and London: Duke University Press, 2010. p. 182-196.

GAYOL, S. y Kessler, G. Muertes que no importan. Una mirada sociohistórica sobre los casos que marcaron la argentina reciente. Buenos Aires: Siglo veintiuno editores, 2018.

GONZÁLEZ RODRÍGUEZ, S. Huesos en el desierto. Barcelona: Anagrama, 2002.

MONÁRREZ FRAGOSO, J. E. La cultura del feminicidio en Ciudad Juarez, 1993-1999.

Frontera Norte, v. 12, n. 23, p. 87-117, 2000.

MONÁRREZ FRAGOSO, J. E. The victims of the Ciudad Juarez Feminicide. In: FREGOSO, R. y BEJARANO C. (eds.). Terrorizing Women. Feminicide in the Américas. Durham and Lond on: Duke University Press, 2010. p. 59-69.

SEGATO, R. L. La escritura en el cuerpo de las mujeres asesinadas en Ciudad Juárez. Territorio, soberanía y crímenes de segundo estado. Buenos Aires: Tinta Limón, 2013.

SEGATO, R. Femigenocidio y feminicidio: una propuesta de tipificación. Revista

Herramienta, $\quad$ v. 2012 49, Disponible en: http://repositorio.ciem.ucr.ac.cr/jspui/bitstream/123456789/151/1/RCIEM132.pdf

Acceso el: 15/09/2021.

SEGATO, R. La guerra contra las mujeres. Buenos Aires: Tinta limón, 2016.

WASHINGTON VALDEZ, D. Cosecha de mujeres: Safari en el desierto mexicano. México City: Océano, 2005. 
ZAVALA, O. Delirios de interpretación: Las mitologías de la violencia de Sergio González Rodríguez. Hispanófila, v. 178, n. 1, p. 115-133, 2016.

ŽIŽEK, S. Violence. Six Sideways Reflections. London: Profile Books, 2008. 